\title{
Mercado interestadual de carvão vegetal no estado do Tocantins
}

\section{Interstate market of charcoal in Tocantins state}

\author{
Jader Nunes Cachoeira ${ }^{(1)}$, Allan Deyvid Pereira da Silva ${ }^{(2}{ }^{2}$, Lawrence Nóbrega de Oliveira ${ }^{3}$, Eduardo \\ Ganassoli Neto ${ }^{4}$, Marcos Giongo ${ }^{10}{ }^{5}$, Antonio Carlos Batista ${ }^{6}$
}

${ }^{1}$ Doutorando em Engenharia Florestal, Universidade Federal do Paraná, Curitiba, (63) 3311-1694, jadernunes@uft.edu.br; ${ }^{2}$ Doutorando em Engenharia Florestal, Universidade Federal do Paraná, Curitiba, (63) 3311-1694, allanuft@ gmail.com; ${ }^{3}$ Mestre em Ciências Florestais e Ambientais, Instituto Brasileiro do Meio Ambiente e dos Recursos Naturais Renováveis, Brasília, (61) 3316-1818, eng.lawrencenobrega@gmail.com; ${ }^{4}$ Mestre em Engenharia Florestal, Universidade Federal do Paraná, Curitiba, (63) 3311-1694, eduardo.florestal@uft.edu.br; ${ }^{5}$ Doutor em Engenharia Florestal, Universidade Federal do Tocantins, Gurupi, (63) 3311-1616, giongo@uft.edu.br; ${ }^{6}$ Doutor em Engenharia Florestal, Universidade Federal do Paraná, Curitiba, (41) 3360-4230, batistaufpr@gmail.com.

\section{A R T I G O}

Recebido: 31/01/2019

Aprovado: 19/03/2019

\section{Palavras-chave:}

Cerrado

Combustível de Madeira

Consumo

Reflorestamento

\section{R E S U M O}

A produção de carvão vegetal proveniente das florestas nativas tem pressionado os biomas em especial o Cerrado, cuja devastação da vegetação tem mantido carvoarias com destino para as siderúrgicas brasileiras. A reposição florestal é uma ferramenta de gestão ambiental utilizada para diminuir a pressão sobre os recursos naturais por meio do reflorestamento. Dados da produção de carvão vegetal permitem estipular a quantidade de créditos de reposição florestal original, para compensar a utilização dos recursos naturais. $\mathrm{O}$ objetivo com este trabalho foi apresentar o panorama atual da produção e dos principais consumidores e destinos de carvão vegetal proveniente de floresta nativa do estado do Tocantins. Como fonte de dados utilizou-se os Documentos de Origem Florestal cedidos pelo Instituto Brasileiro do Meio Ambiente e dos Recursos Naturais Renováveis (IBAMA) durante os anos de 2009 a 2016. Com os dados dispostos em planilha eletrônica, aplicou-se a estatística descritiva. Para a conversão da quantidade de carvão produzido em áreas de florestas plantadas, originadas da reposição florestal, adotou-se os valores estipulados na Resolução $\mathrm{n}^{\circ}$. 28, de 22 de novembro de 2011, do Conselho Estadual do Meio Ambiente do Tocantins (COEMA-TO). Conclui-se que o estado do Tocantins apresentou um cenário de constante crescimento da produção de carvão vegetal nativo, com uma produção média anual de 2009 a 2013 de 546.071,3 metros de carvão, diminuindo para 145.128 m de 2014 a 2016, tendo como principal consumidor o estado de Minas Gerais, que consumiu 77,01\% de sua produção no período de 2009 a 2016.

\section{A B S T R A C T}

The production of charcoal deriving from native forests has been putting pressure on different biomes, mainly the Cerrado one, where the vegetation has been devastated to supply charcoal mining companies focused on Brazilian steel plants. Forest replenishment is an environmental management tool used to reduce pressure on natural resources, through reforestation. Data on the production of charcoal allow stipulating the amount of original forest replenishment credits to offset the use of natural resources. The objective of this work was to the current charcoal production scenario and the main consumers of charcoal deriving from native forests in Tocantins State. Forest Origin Documents regarding the period from 2009 to 2016 were provided by the Brazilian Institute of Environment and Renewable Natural Resources (IBAMA - Instituto Brasileiro do Meio Ambiente e dos Recursos Naturais Renováveis) and used as data sources. Data were inserted in a spreadsheet and subjected to descriptive statistics. Values stipulated in Resolution $\mathrm{n}^{\circ}$. 28, of November 22, 2011, of the State Environmental Council of Tocantins (COEMA-TO Conselho Estadual do Meio Ambiente do Tocantins), were used to convert the amount of charcoal produced in areas of planted forests originated from forest replenishment. Tocantins State presented a scenario of constant native charcoal production increase. The annual mean production was 546,071.3 mdc (meters of charcoal) from 2009 to 2013 and it decreased to 145,128 mdc from 2014 to 2016. The main destination was Minas Gerais State, which consumed $77.01 \%$ of its production from 2009 to 2016.

\footnotetext{
Revista Verde

ISSN 1981-8203

Pombal, Paraíba, Brasil
}

v. 14, n.2, abr.-jun, p.258-265, 2019

doi: 10.18378/rvads.v14i2.6351

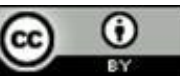




\section{INTRODUÇÃO}

Segundo a Organização das Nações Unidas para a Alimentação e a Agricultura (FAO, 2017) a produção mundial de combustível de madeira, incluindo madeira para carvão, de 2011 a 2015, foi superior a 09 bilhões de $\mathrm{m}^{3}$, sendo boa parte destinada para biomassa (energia). O carvão vegetal é um dos redutores energéticos mais importantes da indústria siderúrgica nacional (SANTOS; HATAKEYAMA, 2012). Em 2014, 19\% do carvão vegetal consumido no Brasil provieram de madeira oriunda de florestas naturais. Em 2015, aproximadamente $71,5 \%$ do carvão vegetal destinaram-se ao setor siderúrgico (IBÁ, 2015).

Apesar do rendimento da silvicultura, as plantações florestais homogêneas não são capazes de suprir toda a demanda das empresas, havendo um déficit anual médio de aproximadamente $47 \%$, que é suprido com florestas naturais, sendo o Cerrado um dos principais biomas fornecedores do carvão vegetal (AMS, 2012). Suas matas começaram a abastecer as carvoarias há mais de um século, apresentandose como um dos ecossistemas mais ameaçados, em função do aumento da produção de carvão vegetal (INSTITUTO ETHOS, 2012).

Devido à necessidade de se manter os recursos florestais, foi instituída a reposição florestal, que apesar de pouco conhecida, traz a solução para a manutenção da biomassa como fonte energética e como único meio de se manter a sustentabilidade da produção do ferro-gusa brasileiro, além de promover aumento da área reflorestada na região de consumo, melhorar a oferta de empregos no campo, diminuição da exploração predatória sobre os remanescentes florestais naturais e a manutenção da biodiversidade (SILVA, 2010; SABBAG, 2011).

A obrigação de fazer plantios em razão da retirada de árvores de mata nativa, bem como a de manter um estoque próprio e suficiente, consta no Novo Código Florestal (Lei n. 12.651, de 25 de maio de 2012), no Decreto Federal 5.975, de 30 de novembro de 2006 e na Instrução Normativa $n^{\circ}$ 06, de 15 de dezembro de 2006, do Ministério do Meio Ambiente (BRASIL, 2006, 2012). Os grandes consumidores dos recursos florestais são obrigados por estabelecer plantações arbóreas, as quais permitem repor a mata nativa explorada, e eliminar a necessidade de recorrer às florestas nativas (FISCHER, 2007; BRITO et al., 2016; LOPES et al., 2016).

Com base na Resolução n. 53, de 05 de novembro de 2014, do Conselho Estadual do Meio Ambiente do estado do Tocantins (COEMA - TO), os créditos de reposição florestal, oriundos de plantios da reposição obrigatória realizados de forma direta serão concedidos em, $60 \%$ posterior à implantação e $40 \%$ um ano após a primeira concessão de créditos do plantio, onde, o volume máximo para a concessão inicial do crédito será de $150 \mathrm{~m}^{3} \mathrm{ha}^{-1}$ para plantios florestais monoespecíficos e $250 \mathrm{~m}^{3} \mathrm{ha}^{-1}$ para plantios com espécies nativas (TOCANTINS, 2014).

Diante do cenário de constante consumo de recursos naturais, notadamente o consumo de carvão vegetal nativo e, tendo em vista que $91 \%$ do território do estado de Tocantins pertencem ao bioma Cerrado, faz-se necessário a obtenção de dados sobre a produção e o mercado consumidor interestadual deste componente energético e a quantidade de crédito de reposição florestal gerados. Ante o exposto, o objetivo com este trabalho foi traçar o perfil do mercado consumidor interestadual de carvão vegetal originado de florestas nativas no Estado de Tocantins, estimando a quantidade de créditos de reposição florestal originado durante o período de 2009 a 2016.

\section{MATERIAL E MÉTODOS}

Para o presente estudo realizou-se uma pesquisa em fontes de dados secundários constantes nos anuários e relatórios de empresas e órgãos, públicos e privados, de competência estadual e/ou federal, para analisar as características da produção e do mercado de carvão vegetal oriundos de florestas nativas, focando o cenário durante o período de 2009 a 2016.

Diante da ausência de informações publicadas por parte das Secretarias Estaduais e de organismos oficiais no estado do Tocantins, como o Instituto Natureza do Tocantins (NATURATINS), o mecanismo principal para a obtenção dos dados, para aferir a produção e o mercado interestadual do carvão vegetal nativo no estado, foram os dados dos Documentos de Origem Florestal (DOF) relativos aos anos de 2009 a 2016.

O Instituto Brasileiro do Meio Ambiente e dos Recursos Naturais Renováveis (IBAMA) caracteriza o sistema DOF como mecanismo de controle e monitoramento de transporte de produtos/subprodutos florestais, o qual integra os documentos Estaduais e Federais, instituído pela Portaria $\mathrm{n}^{\circ}$ 253, de 18 de agosto de 2006, do Ministério do Meio Ambiente (MMA), representando a licença obrigatória para o controle do transporte de produto e subproduto florestal de origem nativa, inclusive o carvão vegetal nativo, em substituição à Autorização de Transporte de Produtos Florestais (ATPF) (IBAMA, 2010).

Os dados do sistema DOF-IBAMA (2009-2016) foram extraídos e exportados para planilha eletrônica, onde as variáveis avaliadas foram: local de origem e destino; data de emissão; quantidade de documentos emitidos por ano; tipo de transporte; distância da origem ao destino; tipo de produto/subproduto florestal e volume anual, também, utilizou-se a ferramenta tabela dinâmica.

$\mathrm{Na}$ planilha eletrônica, os valores de produção de carvão, que no DOF estão em mdc (metros de carvão), foram convertidos em $\mathrm{m}^{3}$. O valor de equivalência aplicado na conversão seguiu o definido pela Sociedade Brasileira de Silvicultura (SBS), em que 1 mdc equivale a $1,3 \mathrm{~m}^{3}$ (SBS, 2006). Para a quantificação dos créditos de reposição florestal, os dados de carvão vegetal nativo $\left(\mathrm{m}^{3}\right)$ foram convertidos em área de reposição florestal. Para esta conversão, adotou-se as quantidades estipuladas pela Resolução nº. 28, de 22 de novembro de 2011, do COEMATO, o qual estabelece que, a concessão dos créditos deve ser baseada na estimativa da produção da floresta. Esta Resolução determina que para plantios florestais monoespecíficos o volume máximo para a concessão inicial do crédito será de $150 \mathrm{~m}^{3} \mathrm{ha}^{-1}$ e $250 \mathrm{~m}^{3} \mathrm{ha}^{-1}$ para plantios com espécies nativas (TOCANTINS, 2011).

\section{RESULTADOS E DISCUSSÃO}

A Tabela 1 apresenta o volume total por ano de carvão vegetal, produzidos com espécies nativas no estado do Tocantins e as movimentações desse produto para os estados 
consumidores. Ao todo, durante o período de 2009 a 2016 , 3.165.730 mdc foram comercializados pelos produtores do estado do Tocantins.

Depreende-se da Tabela 1 que do ano de 2009 para 2013 houve crescente consumo desta fonte energética, saltando de 291.190 mdc em 2009 para 723.200 mdc em 2013, média de $108.002 \mathrm{mdc}$ a mais por ano. No entanto, houve decréscimo significativo nos anos seguintes a 2013. De 2013 a 2014 a diminuição foi de $53 \%$ (384.893 mdc) no consumo do carvão originado do estado do Tocantins, sendo que, em 2016 o valor foi $97 \%$ a menos que o produzido em 2013. Quando comparados com o total consumido de todo o período a redução foi, respectivamente, de 12,20 e $22 \%$, nos anos de 2014, 2015 e 2016, em relação a 2013. O estado de Minas Gerais esteve posicionado hegemonicamente como o maior mercado consumidor de carvão vegetal do Tocantins, correspondendo a 77,01\% de toda a produção tocantinense nos oito anos avaliados. O estado do Maranhão ocupa a segunda posição com $12,17 \%$ desse total, seguido pelo Pará com $8,75 \%$ e outros (MS; DF; BA; PE; PI; CE; SP) que juntos consumiram apenas $0,68 \%$ do carvão vegetal nativo produzido no Tocantins (Tabela 1).

Tabela 1. Volume total e principais destinos de carvão vegetal nativo do estado do Tocantins.

\begin{tabular}{|c|c|c|c|c|c|c|}
\hline \multirow{3}{*}{ ANO } & \multicolumn{5}{|c|}{ DESTINOS } & \multirow{2}{*}{ Total anua } \\
\hline & Minas Gerais & Maranhão & Pará & Goiás & OUTROS* & \\
\hline & \multicolumn{6}{|c|}{$1000 \mathrm{mdc}^{* *}$} \\
\hline 2009 & 156,45 & 90,91 & 41,34 & 0,14 & 2,36 & 291,19 \\
\hline 2010 & 331,51 & 80,04 & 10,25 & 1,11 & 8,09 & 431,00 \\
\hline 2011 & 511,48 & 59,11 & 1,50 & 0,15 & 3,40 & 575,63 \\
\hline 2012 & 670,92 & 31,04 & 2,96 & 2,98 & 1,45 & 709,34 \\
\hline 2013 & 639,01 & 60,49 & 7,60 & 9,84 & 6,27 & 723,20 \\
\hline 2014 & 121,78 & 21,41 & 185,66 & 7,42 & 2,04 & 338,31 \\
\hline 2015 & 2,72 & 33,18 & 27,86 & 8,25 & 4,12 & 76,12 \\
\hline 2016 & 4,21 & 9,04 & & 5,16 & 2,55 & 20,96 \\
\hline TOTAL & $2.438,07$ & 385,20 & 277,15 & 35,04 & 30,27 & $3.165,73$ \\
\hline
\end{tabular}

*Mato Grosso do Sul (MS); Brasília (DF); Bahia (BA); Pernambuco (PE); Piauí (PI); Ceará (CE); São Paulo (SP). ** mdc (metros de carvão). Fonte: Adaptado do DOF-IBAMA (2009-2016).

Os estados do Pará e Maranhão apresentaram quedas de consumo anuais subsequentes, chegando a patamares de $0,26 \%$ e 4,38\%, respectivamente, para os anos de 2011 e 2012, ao passo que o estado de Minas Gerais obteve acréscimo de consumo, chegando a $94,58 \%$ de toda a produção de carvão nativo tocantinense do ano de 2012 (Tabela 1). Todavia, no período de 2014 a 2016 houve inversão nos padrões de consumo do carvão originado do Tocantins. O estado de Minas Gerais deixou de ser o maior consumidor, possivelmente em razão do aumento das áreas de plantios florestais. Em 2014, o estado do Pará foi o principal destino do carvão tocantinense, visto que foram enviados $54,88 \%$ do carvão produzido no mesmo ano, seguido dos estados de Minas Gerais e Maranhão. O mesmo não se repetiu em 2015, neste ano, o estado do Maranhão assumiu a primeira posição, tendo consumido $43,58 \%$ da produção tocantinense de 2015.

O maior consumo de carvão vegetal por parte de Minas Gerais está estritamente ligado a maior parte do polo siderúrgico do país, concentrada no estado. Ainda, o setor siderúrgico brasileiro é o único no mundo que utiliza carvão vegetal como insumo termorredutor para transformação do minério ferro em ferro-gusa (VITAL; PINTO, 2011; IABr, 2014; OLIVEIRA; SPERB, 2016). Já a região dos Carajás, entre o Maranhão e norte do estado do Pará, apresenta particularidades, caracteriza-se mais como polo extrativista do que propriamente siderúrgico (MONTEIRO, 2006; VITAL; PINTO, 2011; CHAGAS, 2011). No estado de Minas Gerais foram produzidas 2,914 mil toneladas de ferro-gusa em 2014 e 2,562 mil toneladas em 2015. No ano de 2014, 5\% do total de carvão consumido tiveram origem de outros estados, dos quais 2\% (403.050,30 mdc) foram produzidos das florestas nativas (IEF, 2014, 2015; SINDIFER, 2015; BRASIL, 2016).
No contexto nacional, informações da produção da extração vegetal e da silvicultura elucidam que em 2015 todos os produtos madeireiros do extrativismo vegetal apresentaram decréscimo na quantidade produzida, a exemplo do carvão vegetal que no comparativo 2014-2015 teve decréscimo de 21,9\% (IBGE, 2015). A diminuição no consumo de carvão vegetal nativo do estado do Tocantins pode estar relacionada com a mudança das normas legais quanto à necessidade das indústrias, particularmente as siderúrgicas, sejam autossustentáveis. Além disso, existe fatores como a demanda industrial, o preço e a atuação de órgãos de controle ambiental e fiscalizadores, que ora liberam abertura de áreas para a agricultura, ora intensificam a fiscalização com a aplicação de multas e fechamento de serrarias e carvoarias (CAMIOTO; REBELATTO, 2014; IBGE, 2015).

Neste aspecto, entrou em vigor, em 2012, o Novo Código Florestal, Lei n.12.651, de 25 de maio de 2012, que determina as pessoas físicas ou jurídicas que utilizam matériaprima florestal em suas atividades o dever de suprirem-se de recursos oriundos de: a) florestas plantadas; b) Plano de Manejo Florestal Sustentável (PMFS) de floresta nativa; c) supressão da vegetação nativa e; d) outras formas de biomassa florestal, bem como a obrigação das empresas industriais que utilizam grande quantidade de matéria-prima florestal de elaborar e implementar um Plano de Suprimento Sustentável (PSS), sendo que neste caso, as siderúrgicas, metalúrgicas ou outras que consumam grandes quantidades de carvão vegetal ou lenha, estabelecerá a utilização exclusiva de matéria-prima oriunda de florestas plantadas ou de PMFS (BRASIL, 2012).

Em detrimento às novas imposições legais, as associadas do Instituto Aço Brasil (IABr) assinaram, em 2012, o Protocolo de Sustentabilidade do Carvão Vegetal que, dentre as diretrizes, estabelece a conclusão, em até quatro anos, do pleno atendimento de estoques florestais às respectivas 
demandas de produção por meio de plantio próprio ou plantio de terceiros (IABr, 2013, 2014). Em 2013, 88,7\% da madeira para produção de carvão vegetal teve origem em floresta plantada própria, $7,7 \%$ em floresta plantada de terceiros e 3,6\% em resíduos florestais legalizados (CARVALHO et al., 2015).

Ante a entrada em vigor da Lei n. 12.651/2012, foi promulgada a Lei n. 20.922, de 16 de outubro de 2013 (Código Florestal do estado de Minas Gerais), definindo o ano de 2018 como prazo final do carvão vegetal não renovável no setor siderúrgico de Minas Gerais. Esta Lei determina que a pessoa física ou jurídica poderá consumir produto ou subproduto de formação nativa, desde que oriundos de uso alternativo do solo, nos percentuais de seu consumo anual total: a) $15 \%$ até o final do ano de 2013; b) 10\%, de 2014 a 2017 e; c) 5\%, a partir de 2018. Mais precisamente, estipula que as empresas de base florestal dos segmentos de aço e ferro, entre outros, estabelecerão a utilização exclusiva de matéria-prima oriunda de florestas plantadas ou de plano de manejo florestal sustentável (MINAS GERAIS, 2013).

Comparando os valores consumidos do carvão vegetal nativo originado do Tocantins pelo estado de Minas Gerais com os percentuais fixados no Código Florestal Mineiro (Lei n. 20.922/2013), verifica-se que possivelmente a razão do consumo ter sido reduzido dos 639.011,6 mdc em 2013 para 121.781,9 mdc em 2014, está relacionada aos percentuais máximos definidos para o consumo de carvão vegetal de origem nativa. Sendo que em 2016, do total de carvão produzido no Tocantins o estado mineiro consumiu apenas $20 \%$ (Tabela 1).

Conforme a OECD (2015) e Mesquita et al. (2016) depois de importantes ciclos de aumento de produção e investimentos, como o período de 2000 a 2007, os setores de mineração e metais, enfrentam atualmente um dos períodos mais difíceis dos últimos vinte anos, com queda abrupta de preços devido à sobreoferta mundial, gerada principalmente pela redução das taxas de crescimento da economia chinesa, o que provocou a diminuição da produção do aço no Brasil e, consequentemente, do consumo de carvão vegetal.

Dentre os maiores municípios consumidores de carvão vegetal produzidos no Tocantins, destacam-se: Sete Lagoas e Divinópolis ambos pertencentes ao estado de Minas Gerais, que, respectivamente, consumiram $38,02 \%$ e $24,86 \%$ do volume total nos últimos oito anos, seguidos pelos municípios de Açailândia (MA), para onde foram transportados 12,13\% de mdc e Marabá (PA) que recebeu $8,75 \%$ do total produzido no período (Tabela 2).

Tabela 2. Principais municípios consumidores do carvão vegetal nativo oriundo do Tocantins (em 1000 mdc).

\begin{tabular}{|c|c|c|c|c|c|c|c|c|c|}
\hline Município-Estado & 2009 & 2010 & 2011 & 2012 & 2013 & 2014 & 2015 & 2016 & Total \\
\hline Sete Lagoas - MG & 55,20 & 185,49 & 308,94 & 332,59 & 266,98 & 54,39 & - & & $1.203,59$ \\
\hline Divinópolis - MG & 76,63 & 98,14 & 105,23 & 227,48 & 238,41 & 40,92 & & 0,18 & 786,98 \\
\hline Açailândia - MA & 89,86 & 80,04 & 59,11 & 31,04 & 60,49 & 21,41 & 33,18 & 9,04 & 384,16 \\
\hline Marabá - PA & 41,34 & 10,25 & 1,50 & 2,96 & 7,60 & 185,66 & 27,83 & & 277,13 \\
\hline Itaúna - MG & 4,99 & & 34,64 & 41,00 & 56,56 & 13,46 & & & 150,63 \\
\hline Pedro Leopoldo - MG & 3,07 & & 13,56 & 38,59 & 53,58 & 5,42 & 1,49 & 4,03 & 119,74 \\
\hline Maravilhas - MG & 1,66 & 8,23 & 9,43 & 5,92 & 16,02 & 5,29 & & & 46,53 \\
\hline Pitangui - MG & 3,93 & 2,27 & 19,64 & 14,77 & 0,03 & & & & 40,64 \\
\hline Bom Despacho - MG & 3,76 & 6,74 & 7,87 & 7,61 & & & & & 25,98 \\
\hline São Gonçalo do Pará-MG & 0,92 & 7,02 & 1,75 & 2,66 & 7,44 & 1,19 & 1,20 & & 22,17 \\
\hline
\end{tabular}

Fonte: Adaptado de DOF/IBAMA (2009-2016).

O estado de Minas Gerais concentra o maior polo siderúrgico do país. Fazem parte do polo guseiro oeste (Divinópolis-MG) quinze municípios, com 45 fornos e capacidade de produção de 3,4 milhões de $\mathrm{t}^{\mathrm{ano}}{ }^{-1}$. O polo guseiro do noroeste (Sete Lagoas-MG) é formado por cinco municípios que totalizam 48 fornos com capacidade de produção de 4,1 milhões de $\mathrm{t}_{\text {ano }}{ }^{-1}$ (REZENDE; SANTOS, 2010; SINDIFER, 2015).

A partir de meados dos anos oitenta surgiram nos estados do Pará e do Maranhão, em função da estrada de ferro e do porto no litoral maranhense, o novo polo de produção de ferro-gusa, denominado Complexo Carajás, cuja produção siderúrgica a partir do ano de 2006 ultrapassou a região sudeste, detendo em 2007, 62\% das exportações brasileiras (UHLIG et al., 2008; QUARESMA, 2009). No estado do Pará estão localizadas 10 usinas de ferro-gusa, com 21 altosfornos, concentradas no município de Marabá, enquanto no Maranhão, o polo siderúrgico é formado por sete usinas, em sua maioria sediadas na região distrital de Açailândia (cinco empresas). Em conjunto, Maranhão e Pará detém $40 \%$ da capacidade instalada brasileira de produção de gusa (QUARESMA, 2009; VITAL; PINTO, 2011).

Nos anos de 2015 e 2016 houve um nítido decréscimo no consumo de carvão vegetal tocantinense (Tabela 2). No entanto, isto não significa ausência do consumo de carvão vegetal e paralisação da produção de ferro-gusa. Em 2014, a produção total de carvão vegetal no Brasil foi de 7.240.423 toneladas, onde, $14 \%$ advieram da extração vegetal (florestas nativas), enquanto em 2015, foi de 6.187.311 toneladas, com $13 \%$ provenientes de florestas nativas (IBGE, 2015; BRASIL, 2016).

O município de Arraias seguido pelo município de Formoso do Araguaia foram os municípios tocantinenses que mais produziram o carvão vegetal nativo do estado durante o período de 2009 a 2016. O primeiro produziu $254.874,72$ mdc, representando $8,05 \%$ do total produzido e comercializado, mas que, no contexto nacional, foi o $18^{\circ}$ município mais produtor em 2015 (IBGE, 2015). Os cinco municípios tocantinenses que mais produziram este recurso energético se encontram na região sul do estado (Tabela 3 ).

Uma vez que o principal destino do carvão vegetal nativo do Tocantins foram as indústrias siderúrgicas, em especial o polo mineiro, o incremento da produção de gusa até 2012 foi sustentado, em parte, pelo carvão oriundo de florestas nativas. Estes, por sua vez, foram necessários à ampliação de áreas agricultáveis nas regiões de fronteira agrícola no Brasil. No Norte, compreendendo os estados do Pará e Tocantins, com forte expansão da agropecuária, do Centro-Oeste, principalmente na "franja" amazônica do estado do Mato Grosso, abrangendo também o Tocantins. Sul 
do Maranhão e do Piauí e oeste da Bahia, devido ao intenso incremento na expansão das áreas de pastagens e dos plantios de soja e cana-de-açúcar (TOCANTINS, 2009; REZENDE; SANTOS, 2010). Dos municípios produtores que constam na Tabela 3, oito municípios, sendo eles: Arraias, São Valério da
Natividade, Conceição do Tocantins, Natividade, Taguatinga, Paranã e Chapada da Natividade, estão localizados na microrregião de Dianópolis, região sudeste do estado e concentraram, no período de estudo, $31,51 \%$ da produção total do carvão nativo.

Tabela 3. Relação da produção de carvão vegetal por município do estado do Tocantins (em 1000 mdc).

\begin{tabular}{|c|c|c|c|c|c|c|c|c|c|c|}
\hline Municípios & 2009 & 2010 & 2011 & 2012 & 2013 & 2014 & 2015 & 2016 & Total & $\%$ \\
\hline Arraias & 15,27 & 35,57 & 64,58 & 56,25 & 53,73 & 27,65 & 1,83 & & 254,88 & 8,1 \\
\hline Formoso do Araguaia & 11,13 & 34,14 & 48,25 & 61,09 & 56,21 & 19,38 & 1,46 & 1,29 & 232,95 & 7,4 \\
\hline Peixe & 8,05 & 11,45 & 23,74 & 44,11 & 41,08 & 18,89 & 2,19 & 0,24 & 149,73 & 4,7 \\
\hline Dueré & 9,89 & 17,84 & 22,13 & 31,07 & 31,72 & 16,39 & 1,89 & 0,83 & 131,77 & 4,2 \\
\hline São Valério da Natividade & 3,95 & 18,97 & 44,12 & 19,50 & 24,70 & 13,87 & 2,85 & & 127,96 & 4 \\
\hline Cristalândia & 9,62 & 17,76 & 20,17 & 23,00 & 25,62 & 20,49 & 4,01 & 2,80 & 123,46 & 3,9 \\
\hline Araguaçu & 4,53 & 11,29 & 25,74 & 31,09 & 23,32 & 8,23 & 0,60 & & 104,78 & 3,3 \\
\hline Conceição do Tocantins & 1,73 & 6,62 & 12,87 & 26,07 & 32,74 & 8,81 & 0,20 & & 89,05 & 2,8 \\
\hline Natividade & 2,42 & 23,25 & 11,66 & 19,13 & 17,07 & 9,40 & 2,18 & & 85,09 & 2,7 \\
\hline Sandolândia & 3,63 & 4,17 & 15,17 & 14,59 & 39,65 & 5,14 & 0,77 & & 83,11 & 2,6 \\
\hline Bom Jesus do Tocantins & 4,20 & 13,44 & 12,74 & 12,51 & 12,43 & 14,40 & 11,62 & 0,10 & 81,44 & 2,6 \\
\hline Taguatinga & 5,17 & 15,37 & 16,95 & 22,93 & 17,83 & 3,18 & & & 81,43 & 2,6 \\
\hline Paranã & 9,30 & 6,51 & 4,99 & 26,42 & 20,63 & 11,50 & & & 79,35 & 2,5 \\
\hline Santa Rita do Tocantins & 4,94 & 8,32 & 9,34 & 20,95 & 8,04 & 16,98 & 5,90 & 3,85 & 78,32 & 2,5 \\
\hline Jau do Tocantins & 6,00 & 9,70 & 8,36 & 19,49 & 19,19 & 10,68 & 3,15 & 0,87 & 77,44 & 2,5 \\
\hline Ponte Alta do Bom Jesus & 5,47 & 9,60 & 17,16 & 12,60 & 16,90 & 9,48 & 0,58 & & 71,79 & 2,3 \\
\hline Aliança do Tocantins & 3,44 & 6,28 & 1,59 & 28,18 & 16,32 & 9,98 & 0,60 & & 66,39 & 2,1 \\
\hline Chapada da Natividade & 0,70 & 3,61 & 20,22 & 22,25 & 13,94 & 3,08 & & & 63,81 & 2 \\
\hline Outros* & 181,78 & 177,11 & 195,86 & 218,10 & 252,09 & 110,81 & 36,30 & 10,97 & $1.183,02$ & 37 \\
\hline
\end{tabular}

*Ponte Alta do Tocantins, Dianópolis, Tocantinópolis, Talismã, Gurupi, Sucupira, Santa Maria do Tocantins, Taipas do Tocantins, Brejinho de Nazaré, São Salvador do Tocantins, Presidente Kennedy, Darcinópolis, Lagoa da Confusão, Crixas do Tocantins, São Bento do Tocantins, Almas, Pium, Palmeirópolis, Itacajá, Porto Nacional, Porto Alegre do Tocantins, Araguatins, Figueirópolis, Lavandeira, Goiatins, Monte do Carmo, Barra do Ouro, Cariri do Tocantins, Tupiratins, Centenário, Santa Rosa do Tocantins, Aparecida do Rio Negro, Nova Olinda, Itaguatins, Ananás, Silvanópolis, Ipueiras, Caseara, Cachoeirinha, Alvorada, Wanderlândia, Araguacema, Marianópolis do Tocantins, Rio da Conceição, Novo Alegre, Novo Jardim, Miracema do Tocantins, Piraquê, Guaraí, Divinópolis do Tocantins, Brasilândia do Tocantins, Fatima, Palmeirante, Novo Acordo, Nazaré, Rio Sono, Lizarda, Nova Rosalândia, Axixá do Tocantins, Palmas, Recursolândia e Dois Irmãos do Tocantins. Fonte: Adaptado de DOF/IBAMA (2009-2016).

A exploração extrativista nesta região está ligada ao fato de que parte considerável de sua área é considerada uma das últimas grandes áreas do Cerrado ainda conservadas, por apresentar características não tão adequadas para a agrossilvicultura. Entretanto, possuem vocação para produção de carvão vegetal em detrimento da abertura de áreas para pecuária devido à influência da BR 010 e da TO 050, bem como a algum dinamismo em função da ligação com o oeste da Bahia e a abertura de minas de calcário na região (COSTA, 2008; SOUZA; MATRICARDI, 2011; TOCANTINS, 2009, 2012). A segunda microrregião na produção do carvão vegetal tocantinense é a do rio Formoso e compreende os municípios de Formoso do Araguaia, Dueré, Cristalândia, Araguaçu e Sandolândia, os quais apresentaram destaque na produção no período de 2009 a 2016, responsáveis por $21,36 \%$ do total de carvão produzido.

Os dados da dinâmica da cobertura e uso da terra, indicam que no período 1990-2007 os dez municípios com maior conversão de áreas de vegetação natural em áreas antrópicas, por ordem de ocorrência em termos percentuais no estado do Tocantins, foram: Formoso do Araguaia (3,7\%), Araguaçu (2,9\%), Lagoa da Confusão (2,8\%) e Pium (2,7\%), onde a supressão da vegetação está relacionada com a expansão da agricultura, principalmente de arroz, soja e milho, sendo que o material lenhoso extraído é utilizado para a produção do carvão vegetal, ocorrendo, ainda, o desmatamento para a produção de carvão vegetal para as indústrias siderúrgicas em Minas Gerais, Maranhão e Pará (TOCANTINS, 2009, 2012).
De acordo com a produção total de carvão vegetal nativo no estado (Tabela 1) e, sabendo que para cada $150 \mathrm{~m}^{3}$ de carvão são necessários o plantio de um hectare de espécies monoespecíficos (Resolução do estado do Tocantins, n. 28/2011), o valor em créditos de reposição florestal gerados no estado do Tocantins para que o órgão ambiental pudesse autorizar, por meio do DOF, a disponibilização desta fonte energética, totalizou $27.436,42$ ha, referente ao período de 2009 a 2016 (Tabela 4).

Conforme a Associação Brasileira dos Produtores de Ferroligas e Silício Metálico (ABRAF, 2013) e a Industria Brasileira de Árvores (IBÁ, 2016) nos anos de 2009 a 2015 a área plantada com Eucalyptus e Pinus no estado do Tocantins foi de 45.160, 48.392, 66.352, 109.853, 111.740, 115.994 e 116.630 ha, respectivamente. Dessas áreas, 6, 8, 8, 6, 6, 3 e $1 \%$, respectivamente, no período de 2009 a 2015 foram oriundas do cumprimento da reposição florestal (Tabela 4). Apesar de parecer irrelevante em termos de área, no tocante aos aspectos protecionista e conservacionista, a reposição florestal desempenha uma função crucial por vincular a produção com sua própria matéria prima, qual seja, a silvicultura. As quantidades de áreas plantadas devido à reposição florestal corroboram com os destinos dados à produção florestal dos plantios no Tocantins, vez que, de acordo com a Secretaria do Meio Ambiente e Desenvolvimento Sustentável do Tocantins, a principal utilização da madeira dos plantios de Eucalyptus no estado é para geração de energia (sobretudo à secagem de grãos), produção de carvão para fins siderúrgicos e madeira tratada (TOCANTINS, 2014). 
Tabela 4. Áreas (ha) de plantios monoespecíficos oriundos da reposição florestal obrigatória por estado e ano de consumo.

\begin{tabular}{cccccccc}
\hline ANO & MG & MA & PA & GO & RJ & OUTROS* & TOTAL \\
\hline 2009 & $1.355,89$ & 787,87 & 358,25 & 1,22 & 13,57 & 6,86 & $2.523,65$ \\
2010 & $2.873,05$ & 693,69 & 88,82 & 9,64 & 28,08 & 42,01 & $3.735,29$ \\
2011 & $4.432,81$ & 512,25 & 12,98 & 1,28 & 29,47 & $4.988,79$ \\
2012 & $5.814,61$ & 268,99 & 25,65 & 25,79 & 12,13 & 0,43 & $6.147,62$ \\
2013 & $5.538,10$ & 524,23 & 65,82 & 85,27 & & 54,32 & $6.267,75$ \\
2014 & $1.055,44$ & 185,58 & $1.609,02$ & 64,30 & & 17,66 & $2.932,01$ \\
2015 & 23,58 & 287,52 & 241,41 & 71,49 & & 35,70 & 659,71 \\
2016 & 36,49 & 78,31 & 0,00 & 44,72 & & 22,10 & 181,61 \\
\hline Total & $21.129,98$ & $3.338,43$ & $2.401,96$ & 303,72 & 83,25 & 179,08 & $27.436,42$ \\
\hline
\end{tabular}

*MS; DF; BA; PE; PI; CE; SP.

No biênio 2015-2016, houve uma acentuada queda no consumo de carvão vegetal nativo do Tocantins (Tabela 1), que consequentemente, levou à redução da área plantada de reposição florestal (Tabela 4). Esta diminuição provavelmente está associada com o aumento das áreas plantadas para fins energéticos no país, principalmente no estado de Minas Gerais. Do total de carvão consumido em 2015, 82\% foram produzidos a partir da madeira oriunda de árvores plantadas, totalizando 3,8 milhões de toneladas, ao passo que em 2014, a participação de árvores plantadas na produção desse mesmo produto foi de $81 \%$ (4,29 milhões de toneladas) (IBÁ, 2015, 2016). A evolução da participação da floresta plantada na produção de carvão, de $60 \%$ em 2009 para $82 \%$ em 2015, vem ao encontro dos novos imperativos legais quanto à sustentabilidade por parte das empresas siderúrgicas.

É importante destacar que os dados da reposição florestal no Tocantins é um importante instrumento para gestão dos recursos renováveis, em especial, das fontes de energia como o carvão vegetal, visto que considerando-se as projeções da produção de ferro-gusa de 2014 a 2020 e utilizando-se um consumo específico de carvão vegetal por tonelada de gusa de $740 \mathrm{~kg} \mathrm{t}^{-1}$, o cálculo equivalente para o suprimento de carvão vegetal alcançará, em 2020, os valores mínimo de 8 milhões de toneladas e máximo de 11 milhões anuais (AVILA FILHO, 2014; SCHERER, 2014).

Assim, mantendo-se os valores de rendimento gravimétrico do carvão para os produtores independentes e para as siderúrgicas integradas, sem melhoria do incremento de produtividade florestal, como melhor qualidade do carvão vegetal, estima-se a necessidade, para substituição de mata nativa, em 2020, de um adicional de 106 mil hectares de cultivo anual de florestas plantadas para atender à produção anual de 11 milhões de toneladas de ferro-gusa. Isso significa ter que depender do uso de $40 \%$ de florestas nativas para suprir o carvão vegetal total necessário como termorredutor (CGEE, 2015).

\section{CONCLUSÕES}

O principal destino do carvão vegetal produzido a partir de florestas nativas no estado do Tocantins é o estado de Minas Gerais, seguido pelo estado do Maranhão. Quanto à origem, as regiões que mais produzem o carvão vegetal são as microrregiões de Dianópolis e rio Formoso no sul do Tocantins. Das florestas plantadas no estado do Tocantins, $27.436,42$ ha estão vinculadas ao pagamento dos créditos de reposição florestal.

A acentuada queda no consumo de carvão vegetal nativo do Tocantins está associada ao aumento das áreas plantadas para fins energéticos no país, principalmente no estado de Minas Gerais, bem como ao maior rigor das normas ambientais quanto à obrigatoriedade de que os consumidores desta fonte energética sejam autossustentáveis.

\section{REFERÊNCIAS}

ABRAF, Associação Brasileira de Produtores de Floresta Plantada. Anuário Estatístico da ABRAF 2013 ano base 2012. Brasília, 2013, 142 p.

AMS, Associação Mineira de Silvicultura. Florestas plantadas - um caminho para um desenvolvimento sustentável. Belo Horizonte, 2012.

AVILA FILHO, B. M. Levantamento dos níveis de produção de aço e ferro-gusa, cenário em 2020. Brasília: Centro de Gestão e Estudos Estratégicos, 2014, 63 p.

BRASIL. Planalto. Lei n ${ }^{\circ}$ 12.651, de 25 de maio de 2012. Dispõe sobre a proteção da vegetação nativa; e dá outras providências. Disponível em: <http://www.planalto.gov.br/ccivil_03/_ato2011-

2014/2012/lei/112651.htm>. Acesso em: 20 mar. 2017.

BRASIL. Decreto $\mathrm{n}^{\mathrm{o}}$ 5.975, de 30 de novembro de 2006. Regulamenta os arts. 12, parte final, 15, 16, 19, 20 e 21 da Lei no 4.771 , de 15 de setembro de 1965 , o art. 4o, inciso III, da Lei no 6.938 , de 31 de agosto de 1981, o art. 2o da Lei no 10.650, de 16 de abril de 2003, e dá outras providências. Disponível em:

<http://www.planalto.gov.br/ccivil_03/_ato2004-

2006/2006/decreto/d5975.htm>. Acesso em: 20 mar. 2017.

BRASIL. Ministério de Minas e Energia. Balanço Energético Nacional: 2008. Disponível em: <http://www.mme.gov.br/mme/menu/todas_publicacoes.html >. Acesso em: 20 mai. 2015.

BRASIL. Ministério de Minas e Energia. Balanço Energético Nacional: 2009. Disponível em: <http://www.mme.gov.br/mme/menu/todas_publicacoes.html $>$. Acesso em: 21 mai. 2016.

BRASIL. Ministério de Minas e Energia. Balanço Energético Nacional: 2010. Disponível em: <http://www.mme.gov.br/mme/menu/todas_publicacoes.html >. Acesso em: 21 mai. 2016. 
BRASIL. Ministério de Minas e Energia. Balanço Energético Nacional: 2011. Disponível em: <http://www.mme.gov.br/mme/menu/todas_publicacoes.html >. Acesso em: 20 fev. 2017.

BRASIL. Ministério de Minas e Energia. Balanço Energético Nacional: 2015. Disponível em: <http://www.mme.gov.br/mme/menu/todas_publicacoes.html >. Acesso em: 12 abr. 2017.

BRASIL. Ministério de Minas e Energia. Balanço Energético Nacional: 2016. Disponível em: <http://www.mme.gov.br/mme/menu/todas_publicacoes.html >. Acesso em: 12 abr. 2017.

BRASIL. Ministério de Minas e Energia. Anuário Estatístico do Setor Metalúrgico: 2016. Disponível em: <http://www.mme.gov.br/web/guest/secretarias/geologiamineracao-e-transformacao-mineral/publicacoes>. Acesso em: 10 abr. 2017.

BRASIL. Ministério do Meio Ambiente. Instrução Normativa $\mathrm{n}^{\circ} 6$, de 15 de dezembro de 2006. Dispõe sobre a reposição florestal e o consumo de matéria-prima florestal, e dá outras providências. Disponível em: pesqueiros/instrucao-normativa >. Acesso em: 22 mai. 2015.

BRITO, J. O.; SILVA, F. G.; LEÃO, M. M.; ALMEIDA, G. Chemical composition changes in eucalyptus and pinus woods submitted to heat treatment. Bioresource technology, v.99, n.18, p.8545-8548, 2008. 10.1016/j.biortech.2008.03.069.

CAMioto, F. C.; ReBElatTo, D. A. N. Análise da contribuição ambiental por meio da alteração da matriz energética do setor brasileiro de ferro-gusa e aço. Gestão e Produção, v.21, n.4, p.732-744, 2014.

CARVALHO, P. S. L.; MESQUITA, P. P. D.; ARAÚJO, E. D. G. Sustentabilidade da siderurgia brasileira: eficiência energética, emissões e competitividade. BNDES Setorial, 41, 2015, p.181-236.

CGEE, Centro de Gestão e Estudos Estratégicos. Modernização da produção de carvão vegetal no Brasil: subsídios para revisão do Plano Siderurgia. Brasília: DF, $2015,154 \mathrm{p}$.

CHAGAS, R. C. M. Em busca da sustentabilidade: reflorestamento versus floresta nativa como fonte de carvão vegetal para a guserias ao longo da estrada de ferro Carajás. 2011. 112 f. Dissertação (Mestrado) Universidade Federal do Pará, Belém. 2011.

COSTA, M. S. P. Poder local em Tocantins: domínio e legitimidade em Arraias. 2008. 276 f. Tese (Doutorado em Sociologia) Universidade Nacional de Brasília, Brasília. 2008.

FAO, Food and Agriculture Organization of the United Nations. FAOSTAT. Forestry Production and Trade 2017.
Disponível: < http://www.fao.org/faostat/en/\#data/FO>. Acesso em: 15/05/2018.

FISCHER, A. Incentivos em programas de fomento florestal na indústria de celulose. 2007. 269 f. Tese (Doutorado em Administração) Universidade de São Paulo, São Paulo. 2007.

IBÁ, Indústria Brasileira de Árvores. Anuário Estatístico da IBÁ 2015 - Ano Base 2014. 2015. Disponível em: <http://www.ipef.br/estatisticas/relatorios/anuario-

iba_2015.pdf>. Acesso em: 15 mar. 2017.

IBÁ, Indústria Brasileira de Árvores. Relatório Anual 2016 Ano Base 2015. 2016. Disponível em: <http://iba.org/images/shared/Biblioteca/IBA_RelatorioAnual 2016_.pdf>. Acesso em: 15 mar. 2017.

IEF, Instituto Estadual de Florestas. Relatório do Consumo de Produtos e Subprodutos Florestais - Grandes Consumidores 2014. Disponível em: <http://www.ief.mg.gov.br/images/stories/2015_ARQUIVOS /AREAS_PROTEGIDAS/DOCUMENTOS/Consumo_anual_ 2014.xlsx>. Acesso em: 25 mai. 2017.

IEF, Instituto Estadual de Florestas. Relatório do Consumo de Produtos e Subprodutos Florestais - Grandes Consumidores 2015. Disponível em: < http://www.ief.mg.gov.br/images/stories/2016/IEF/1Grandes_ Consumidores_2015.pdf>. Acesso em: 25 mai. 2017.

IABr, Instituto Aço Brasil. Relatório de sustentabilidade 2013. 2013. Disponível em: <http://www.acobrasil.org.br/site/portugues/sustentabilidade/ downloads/relatorio_sustentabilidade_2013v3.pdf>. Acesso em: 21 mai. 2016.

IABr, Instituto Aço Brasil. Relatório de sustentabilidade 2013. Protocolo de Sustentabilidade do Carvão Vegetal. Rio de Janeiro, 2013. Disponível em: < http://www.acobrasil.org.br/site/portugues/sustentabilidade/d ownloads/resultados-protocolo.pdf $>$. Acesso em: 25 mar. 2017.

IABr, Instituto Aço Brasil. Relatório de sustentabilidade 2013. Relatório de sustentabilidade 2016. 2016. Disponível em: < http://www.acobrasil.org.br/sustentabilidade/>. Acesso em: 21 fev. 2017.

IABr, Instituto Aço Brasil. Relatório de sustentabilidade 2013. Relatório de sustentabilidade 2014. 2014. Disponível em:

<http://www.acobrasil.org.br/site/portugues/biblioteca/Relato rio\%20de\%20Sustentabilidade_2014_web.pdf $>$. Acesso em: 21 fev. 2017.

IBGE, Instituto Brasileiro de Geografia e Estatística. Biomas brasileiros e localidades. 2007. Disponível em <http://www.ibge.gov.br/home/geociencias/default_prod.sht m\#MAPAS >. Acesso em: 10 set. 2015.

IBAMA, Instituto Brasileiro de Meio Ambiente e dos Recursos Naturais Renováveis. DOF: informação estratégica 
para a gestão florestal, período 2007 - 2009. Brasília, DF, 2010 .

INSTITUTO ETHOS. Combate à devastação ambiental e ao trabalho escravo na produção do ferro e do aço. 1. ed. São Paulo: Ed. Fundação Avina, 2012, 135 p.

LOPES, G. A.; BRITO, J. O.; DE MOURA, L. F. Uso energético de resíduos madeireiros na produção de cerâmicas no estado de São Paulo. Ciência Florestal, v.26, n.2, 2016.

MESQUITA, P. P. D.; CARVALHO, P. S. L.; OGANDO, L. D. Desenvolvimento e inovação em mineração e metais. BNDES Setorial, 43, 2016, p.325-361.

MINAS GERAIS (Estado). Lei $\mathrm{n}^{\circ}$ 20.922, de 16 de outubro de 2013. Dispõe sobre as políticas florestal e de proteção à biodiversidade no Estado. Imprensa Oficial Governo do Estado de Minas Gerais, Caderno 1 - Diário do Executivo, Belo Horizonte, MG, 17 out. 2013, n. 195.

MONTEIRO, M. A. Em busca de carvão vegetal barato: o deslocamento de siderúrgica para Amazônia. Novos cadernos NAEA, v.9, n.2, 2006. 10.5801/ncn.v9i2.67.

OECD. Excess Capacity in the Global Steel Industry and the Implications of New Investment Projects. OECD Science, Technology and Industry Policy Papers, n. 18, OECD Publishing, Paris, 2015.

OLIVEIRA, J. C.; SPERB, A. F. N. Analysis of the evolution of the concentration in the Brazilian steel industry among the years of 1991 and 2013. Estudos do CEPE, n.43, p.84-100, 2016.

QUARESMA, L. F. Desenvolvimento de estudos para elaboração do plano Duodecenal (2010-2030) de geologia, Mineração e Transformação Mineral. Produto 33: Cadeia do Ferro-Gusa. Ministério de Minas e Energia, 2009, 58 p.

REZENDE, J. B.; SANTOS, A. C. A cadeia produtiva do carvão vegetal em Minas Gerais: pontos críticos e potencialidades. U.R. EPAMIG ZM, 2010, 80 p.

SABBAG, S. C. Reposição florestal: caminho para o desenvolvimento sustentável da silvicultura tropical. 2011. 159 f. Dissertação (Mestrado), Universidade de Brasília, Brasília. 2011.

SANTOS, S. F. O. M.; HATAKEYAMA, K. Processo sustentável de produção de carvão vegetal quanto aos aspectos: ambiental, econômico, social e cultural. Production Journal, v.22, n.2, p.309-321, 2012. 10.1590/S010365132012005000010 .

SBS, Sociedade Brasileira de Silvicultura. Fatos e Números do Brasil Florestal 2006. Disponível em <http://www.sbs.org.br>. Acesso em: 22 mai. 2017.

SCHERER, W. G. S. Levantamento dos níveis de produção de aço e ferro-gusa, cenário em 2020: Ênfase: uso da energia gerada na combustão dos gases da carbonização. Brasília: Centro de Gestão e Estudos Estratégicos, 2014, 33 p.
SILVA, C. M. Reposição florestal: estudo de caso no Estado de São Paulo. 2010. 39 f. Monografia (Trabalho de Conclusão de Curso), Universidade Federal Rural do Rio de Janeiro, Seropédica. 2010.

SINDIFER, Sindicato da Indústria do Ferro no Estado de Minas Gerais. Anuário 2015. 2015. Disponível em: <http://www.sindifer.com.br/institucional/anuario/anuario_20 15.pdf>. Acesso em: 15 abr. 2017.

SOUZA, G. M.; MATRICARDI, E. A. T. Mapeamento do uso e ocupação do solo nos anos 2000, 2005 e 2010 no município de Arraias, bacia do rio Paranã, Tocantins, Brasil, com dados de sensoriamento remoto. In: XV SIMPÓSIO BRASILEIRO DE SENSORIAMENTO REMOTO, 2011. Anais... Curitiba, PR: INPE p.6450.

TOCANTINS (Estado). Conselho Estadual do Meio Ambiente. Resolução $n^{\circ}$ 53, de 05 de novembro de 2014. Dispõe sobre a atividade de silvicultura em áreas convertidas, reposição florestal, concessão de créditos e dá outras providências. Diário Oficial do Estado do Tocantins, Poder Executivo, Palmas, TO, 14 nov. 2014, n. 4.256.

TOCANTINS (Estado). Plano de Ação para prevenção e controle do desmatamento e queimadas do Estado do Tocantins. Brasília, DF, 2009. 107 p.

TOCANTINS (Estado). Estudo da Dinâmica da Cobertura e Uso da Terra no Estado do Tocantins 1990/2000/2005/2007. BORGES, R.S.T. (Org.). Palmas, TO: SEPLAN, 2012. 264 p.

TOCANTINS (Estado). Secretaria do Meio Ambiente e Desenvolvimento Sustentável do Tocantins. REFORMULAÇÃO DA POLÍTICA ESTADUAL DE FLORESTAS E ELABORAÇÃO DO PLANO ESTADUAL DE FLORESTAS DO TOCANTINS (PEF/TO) - PRODUTO 11 - RELATÓRIO TÉCNICO FINAL. Palmas: TO, 2014, $175 \mathrm{p}$.

UHLIG, A.; GOLDEMBERG, J.; COELHO, S. T. O uso de carvão vegetal na indústria siderúrgica brasileira e o impacto sobre as mudanças climáticas. Revista Brasileira de Energia, São Paulo, vol.14, p.67-85, 2008.

VITAL, M. H. F.; PINTO, M. A. C. Condições para a sustentabilidade da produção de carvão vegetal para fabricação de ferro-gusa no Brasil. BNDES Setorial, 30, 2011, p. 237-297. 